\title{
GEOSTATISTICAL SEISMIC ANALYSIS AND HAZARD ASSESSMENT; UNITED ARAB EMIRATES
}

\author{
D. Al-Dogom ${ }^{1,}{ }^{*}$, K. Schuckma ${ }^{1}$, R. Al-Ruzouq ${ }^{2}$ \\ ${ }^{1}$ Department of Geography, the Pennsylvania State University, USA - aldogomd@ gmail.com \\ ${ }^{2}$ Dept. of Civil and Environmental Engineering, University of Sharjah, UAE
}

Commission VI, WG VI/4

KEY WORDS: Seismic Hazard, Spatio-temporal Analysis, Directional Distribution, Ground Peak Acceleration (GPA), Analytic Hierarchy Process (AHP), United Arab Emirates (UAE)

\begin{abstract}
:
Assessing and analyzing the spatial distribution of earthquake events aids in identifying the presence of clustering and reveals hot and cold spots across the study area. Combining the spatial analysis of earthquake events with other geographical and geophysical parameters leads to more understanding of the vulnerability of critical infrastructure and the demographics of the affected population. This study will use Geographical Information Systems (GIS) to examine the spatiotemporal occurrence of earthquake events throughout the Arabian plate and their effect on the United Arab Emirates (UAE). Spatial pattern analysis techniques, including Moran I and Getis-Ord Gi*, were applied to 115 years of earthquakes (1900-2015) that have occurred throughout the Arabian plate. The directional distribution (standard deviational ellipse) of earthquake magnitudes was analyzed to determine the spatial characteristics and the directional tendency of the earthquakes throughout the Arabian plate. Afterword, geophysical parameters of UAE, specifically Peak Ground Acceleration (PGA), fault line distance, slope, soil type, and geology were ranked, weighted based on its contribution and combined using an Analytic Hierarchy Process (AHP) to identify and locate seismic hazard zones. The resulted Seismic Hazard Zonation Map (SHZM) was classified to five hazard zones ranging from very high to very low. It has been found that Fujairah city sited in the "very High" zone, Sharjah and Dubai cities located from "High" to moderate zones while Abu Dhabi city stands relatively far from seismic hot spots and major faults and placed in the low seismic hazard zone. The results of this study could help improve urban planning and emergency mitigation strategies in UAE.
\end{abstract}

\section{INTRODUCTION}

Earthquakes have a substantial effect on human lives, infrastructures, and economy. Even though they are considered a short-term disaster, their impact in the affected area can last for years. Earthquakes are described by their magnitude, speed of onset, frequency, duration, and geographic location (epicenter location). They can vary in severity from light, that will not be felt, to those strong enough to exterminate people and destroy towns. Measures of seismic activity include earthquake frequency, and magnitude (size) that happened for a period. UAE is considered a low seismic activity area (Aldama-Bustos et al., 2009) where seismic hazards have been classified as insignificant (Pascucci et al., 2008) However, UAE's proximity to major faults and active seismic sources, it's extensive urban development activities and financial investments, and it's rapidly growing population reveal an urgent need to examine and study the region's seismic risk (Al-Ruzouq et al., 2017). During the last decade, UAE established the National Emergency and Crises Management Authority (NCEMA), whose major responsibilities are to coordinate with other response organizations and facilitate the preparation and mitigation procedures related to earthquake disaster (Ncema.gov.ae, 2018). Additionally, UAE emirates have revised building codes to cope more effectively with any predicted earthquake (Harnan, 2013).

Investigating earthquake-event clusters and analyzing spatial distributions could be an important step to assist in modeling earthquake occurrence and micro-zonation of earthquake risk. Spatial pattern analysis techniques have been widely investigated to explore the clusters, spatial patterns, and the directional distribution of the occurrence of the earthquake. (Al-Amri et al.,
1998; Korrat et al., 2006) studied the spatial distribution of earthquake events along the Red Sea region where the occurrence of main earthquakes is distributed over a wide area classified by the existence of rift zones, displacements, and structural breaks. (Al-ahmadi et al., 2013) Conducted spatial statistical analysis to examine the occurrence of earthquakes along the Red Sea floor spreading. Different earthquake catalogs for the period (19002009) have been used to collect earthquake events. Four global statistics (quadrant count analysis, average nearest neighbor, global Moran's I, and Getis- Ord general G.) and three local statistics (Anselin local Moran's I, Getis-Ord Gi*, kernel density estimator) have been used to analyze the occurrences of earthquake events. To examine the geographic distribution of earthquakes, different methods have been applied including directional distribution, central feature, the mean center, and the median center. (Danese M. et al., 2008) Used Kernel Density Estimation Methods as a Geostatistical Approach in the Seismic Risk Analysis of Potenza Hilltop Town (Southern Italy). The topographic map, geological map, geomorphological map, borehole logs, geotechnical laboratory test, geophysical data, historical macro-seismic data at building scale, and historical photographs of damaged buildings and plans of rebuilding (19th century) were used along with Kernel Density Estimation Methods to know seismic risk variability at local level, modelling and visualizing it.

In addition to statistical spatial analysis, different approaches and methodologies have been integrated and automated with the use of GIS and AHP to study and investigate the seismicity activity for a specific area and to develop seismic hazard zonation maps. AHP is an analytical tool that enables researchers to assign weights to tangible and intangible criteria. This method has been 
used in seismic hazard mapping processes and is based on three principles: decomposition, comparative judgment, and synthetization of priorities (Saaty, 1980). AHP can be used subjectively while minimizing inconsistency in judgment, which is considered as one of its advantages over other available methodologies. Also, AHP is usually implemented to provide practical solutions for multi-criteria decision-making problems (Chang et al., 2008). The difficulty of this method appears in the estimation of the input data and their preferences. Several studies have been performed using AHP methodology to evaluate hazard severity based on several related factors at different levels of contribution for each considered factor. (Ansal et al., 2009) used a GIS-based loss assessment model of Istanbul, Turkey to combined deterministic hazard scenarios and probabilistic timedependent hazard assessment, to develop different earthquake scenarios showing the anticipated earthquake structural damage and fatalities. (Liu et al., 2012) presented a GIS-based approach using multi-criteria factors (geological and topographical variables such as rock competence, slope, proximity to drainage, and fracture density) to model earthquake damage zone and the susceptibility of earthquake-related geo-hazards in Sichuan Province, China, throughout the use of overlay weighted analysis.(Cinicioglu et al., 2007) presents an integrated, earthquake-damage assessment by combining the risk from soil structure, liquefaction, landslide, ground shaking, and seismic bearing capacity degradation factors to estimate the area structural and geotechnical characteristics contribution on the earthquake risk. Using GIS platform (Pal et al., 2007) establish Earthquake hazard zonation of Sikkim Himalaya. Geology, Soil, Slope, Rock Outcrop, and Landslides maps for India have been prepared. Using AHP technique, all the geomorphologic, seismological, and the geo-hazard vector layer has been weighted, ranked and overlaid to generate Geo-hazard map. (Erden and Karaman, 2012) analyze earthquake parameters such as Digital elevation model (DEM), soil classification map, and the Fault/focal mechanism), and integrating them using AHP and GIS to generate earthquake hazard map. (Mohanty et al., 2006) presented Seismic Micro-zonation map of Delhi. In their study they identified tiny earthquake-vulnerable zones (Seismic microzonation) using GIS and AHP; different layers (recorded observations of Chamoli earthquake, Topo-sheets, soil classification map, geology classification map, groundwater depth and the residual gravity map) have been classified, ranked, weighted, normalized and finally overlaid in GIS. In these studies, the most important component was a determination of the various factors affecting the seismic severity process. The AHP technique was then utilized to properly assign weights to the various factors based on their importance for seismic severity. For example,

In UAE (Sigbjornsson and Elnashai, 2006) used earthquake catalog and (Ambraseys and Srbulov, 1994; Simpson, 1996) attenuation relationships equations to perform seismic hazard assessment and produce PGA values for Dubai city, UAE. (Malkawi et al., 2007) studied UAE overall seismicity. They considered the seismic events at the Arabian plate and Iranian plate as the reasons for the seismic hazards that can yield to the significant ground motion. They perform probabilistic seismic hazard assessment and generate seismic hazard maps for $15 \mathrm{UAE}$ regions. In their research, they concluded that the north-eastern part of UAE is the most seismic active part. UAE and its surroundings have been delineated into seven seismic source regions by (Abdalla and Al-Homoud, 2004) where modified attenuation relation for Zagros region has been adopted to carry out the seismic hazard assessment for $20 \mathrm{~km}$ interval grid points, followed by developing seismic hazard maps of the studied area based on probable PGA for $10 \%$ probability of exceedance for timespans of 50,100 and 200 years. The study showed that the northern Emirates region is the most seismically active part of UAE, and UAE has moderate to low seismic hazard levels. (Yagoub, 2015) conducted a GIS-based study for UAE northwestern part. Using AHP different layer (Geology, soil, slope, historical earthquake events, fault lines, land use) has been weighted and ranked according to its importance to generate earthquake hazard map. The author found that earthquake events clustered in the Emirate of Fujairah in the eastern part of UAE, moreover a maximum number of earthquake events (49\%) occurred in 2011. The study showed that there is a low risk of high-intensity earthquake expected to hit the study region. Using GIS (Barakat, S. et al., 2008) different layers (population, seismic hazard map, probable PGA contours, shaking hazard maps, hypothetical earthquake scenarios, and a number of the building) has been ranked to assess and compare the risk associated with the adverse consequences of earthquakes in the UAE. The study found that greater number of people theoretically would be affected by an earthquake occurring in the northern UAE relative to an earthquake in the southern UAE. The authors conclude that there is an abundance of weak, and vulnerable infrastructure with little to no seismic protection, and the seismic design practice in the UAE is still immature.

This work suggests a methodology to investigate spatial pattern, clusters and the directional distribution of the occurrence of the earthquake around the Arabian plate from 1900 to 2015 followed by estimation Peak Ground Acceleration (PGA) in UAE. Moreover, AHP that include ranking, weighting, and overlaying of different raster layers PGA, Distance from faults, slope, soil, and geology were used to generate seismic hazard map. The main objectives of this work can be summarized as follows:

1. Perform spatial-temporal statistical analysis for earthquake events within Arabian plates to locate hotspot that affecting UAE along with its directional distribution.

2. Identify and map-related geological, geophysical factors and their weighted contribution in seismic activity.

3. Utilize AHP along with weighted overlay analysis to prepare SHZM for UAE

The next section describes the study area; followed by sections discussing the proposed methodology applied to SHZM for UAE. After that, the results and discussion of applying the proposed methodology; finally, the paper concludes with a summary of major findings and recommendations for future research.

\section{STUDY AREA}

The Arabian Plate located in the northern, eastern hemisphere, Figure1. It is a minor tectonic plate bordered by three different plates. The northern edge of the Arabian plate bordered by the southern region of the Eurasian plate forming the Bitlis suture, the Zagros thrust and the Makaran thrust, moreover it is bordered with the eastern boundary of the Anatolian plate forming a transform boundary called the East Anatolian Fault. As shown in Figure 1, UAE is located at the Arabian plate, western Asia at the southeast end of the Arabian Peninsula on the Arabian Gulf. It lies between $22^{\circ} 30^{\prime}$ and $26^{\circ} 10^{\prime}$ north latitude and between $51^{\circ}$ and $56^{\circ} 25^{\prime}$ east longitudes. The UAE coast stretches for more than $650 \mathrm{~km}(404 \mathrm{mi})$ along the southern shore of the Arabian Gulf. As shown in Figure 2, the framework of proposed methodology relies on two types of data sets as described in the next two subsections; seismic data catalog and geospatial data set that include main fracture lines, DEM, soil and geology maps.

\subsection{Seismic Data Catalog}

Collecting a complete, reliable, and consistent earthquake catalog is important for hazard, risk assessments and for statistical seismicity analysis of the study area. The seismicity of Arabian 
Plate is covered by multiple earthquake databases, in this study, homogenous earthquake catalog of moment-magnitude $(\mathrm{Mw})$ for the Arabian Plate was downloaded from Earthquake Monitoring Centre, Sultan Qaboos University. The downloaded earthquake catalog was prepared by (Deif et al., 2017) it is spatially including the entire Arabian plate and neighboring countries, covering all earthquake sources that can produce a significant hazard for the Arabian Plate land. The catalog extends from 1900 to 2015 with a total number of 13,156 events.

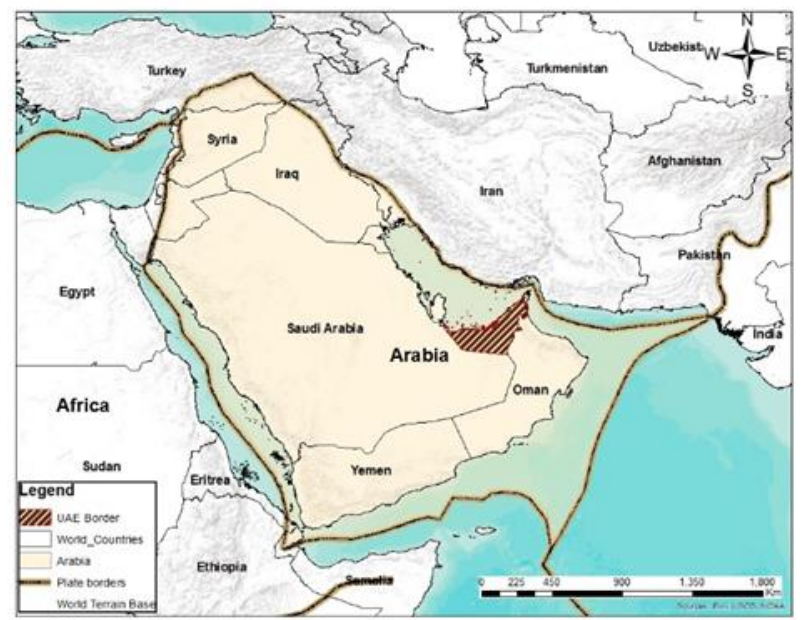

Figure 1. Location map of the study area

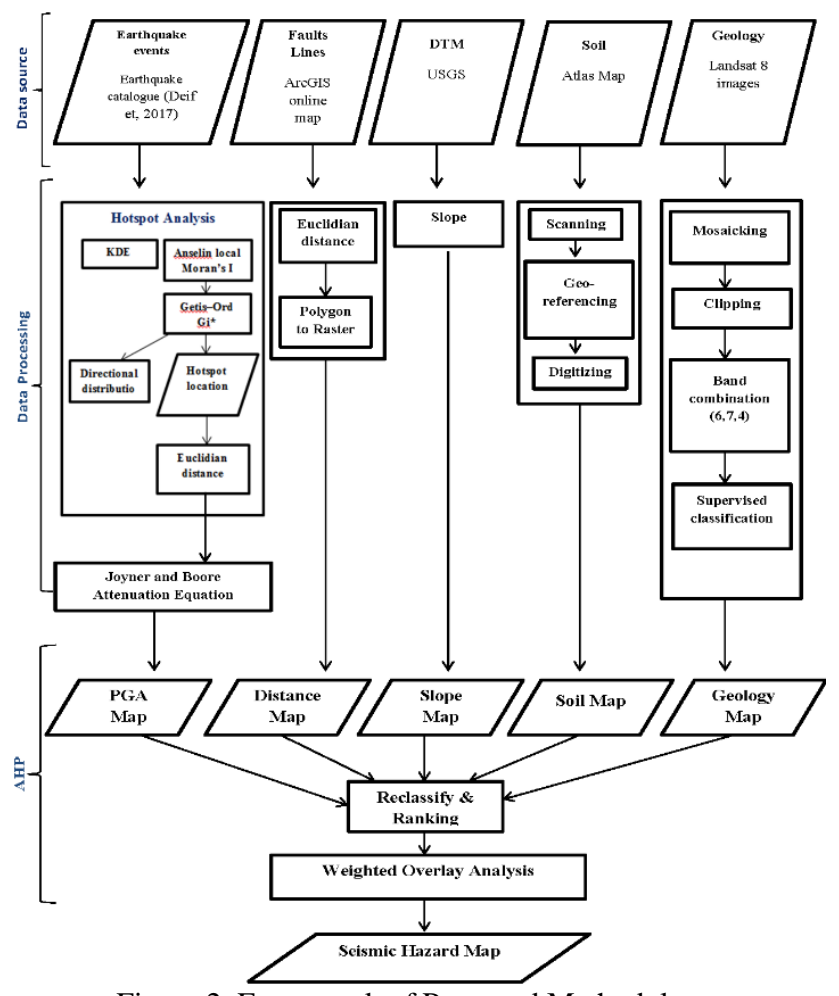

Figure 2. Framework of Proposed Methodology

Table 1, shows a small sample of the earthquake events and part of the associated attributes.

\begin{tabular}{|c|c|c|c|c|}
\hline Date & Time & Latitude & Longitude & $\begin{array}{c}\text { Magnitude } \\
\text { Mw }\end{array}$ \\
\hline $\mathrm{M} / \mathrm{D} / \mathrm{Y}$ & & \multicolumn{2}{|c|}{ Degrees } & \\
\hline $1 / 5 / 1900$ & 0:55:00 & 34.45 & 34.00 & 6.1 \\
\hline $1 / 18 / 1900$ & $5: 29: 00$ & 29.00 & 33.00 & 4.6 \\
\hline $1 / 27 / 1900$ & 2:30:00 & 37.63 & 37.37 & 5.3 \\
\hline $2 / 24 / 1900$ & 0:30:00 & 38.45 & 44.87 & 5.6 \\
\hline $3 / 6 / 1900$ & 17:58:00 & 29.00 & 33.00 & 6.5 \\
\hline $1 / 5 / 1900$ & 0:55:00 & 34.45 & 34.00 & 6.1 \\
\hline
\end{tabular}

Table 1. Sample of the earthquake catalog (Deif et al., 2017)

Throughout the compiling of (Deif et al., 2017) earthquake catalog, the Arabian plate was subdivided into four polygons according to the tectonic regime, seismic activity, and geographic considerations. Different data sources including special studies, local, regional and international catalogs were used to prepare the earthquake catalog. Moment magnitudes (Mw) that provided by sources were given the highest magnitude type priority while earthquakes with magnitude differ from $\mathrm{Mw}$ were converted into the same scale by applying different empirical relationships. Figure 3-a shows the spatial distribution of earthquake events within the earthquake catalog.

\subsection{Geospatial Data}

Vector and raster spatial data used in this study include: faults line location that had been digitized using ArcGIS online fault map, Figure 3-a shows the Zagros and the Makaran thrust location; 30m ground resolution elevation data (ASTER DEM downloaded from USGS, Figure 3-b; digitized soil map based on scanned, georeferenced hardcopy of UAE National atlas soil map, Figure 3-c; geology map prepared based on supervised classification of Landsat 8 images free of cloud cover for the year 2017 downloaded from USGS website page, Figure 3-d.

\section{METHODOLOGY}

Figure 2 shows the framework of the proposed methodology. The first part, section 3.1, relies on spatial analysis of earthquake events within Arabian plates to find Hotspot locations. This process includes Kernel Density, Anselin local Moran's I, GetisOrd $\mathrm{Gi}^{*}$ and directional distribution. Afterword, the Euclidian distance was used to find distances from the hot spot locations and the study area (UAE) which is essential to estimate the PGA based on the attenuation equation motivated by that of Joyner and Boore (Joyner, 1981), section 3.2. The PGA will be represented in $30 \mathrm{~m}$ raster image that would facilitate introducing this factor along with other geophysical factors throughout AHP and weighted overlay analysis, section 3.3. This section, include various geospatial analysis (scanning, georeferencing, digitizing and image classification) to create raster layers that can be used to identify seismic hazard zones. These layers are Euclidian distance map from major faults, slope, and soil and geology maps. Finally, these maps were ranked and weighted based on their contribution to the severity of an earthquake in the study area. The output map was reclassified into five zones ranging from very high to very low. It is important to mention that the seismic scale from "very high" to "very low" is not absolute but to distinguish between various earthquake hazard zones at UAE. 


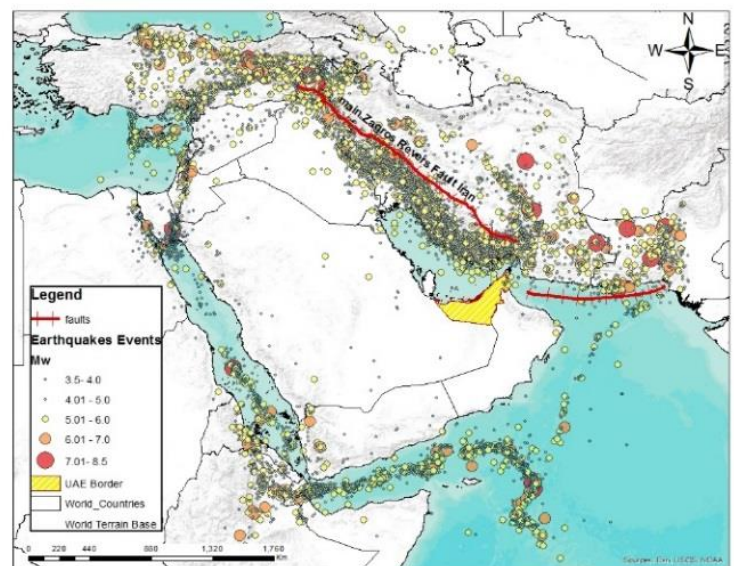

(a)

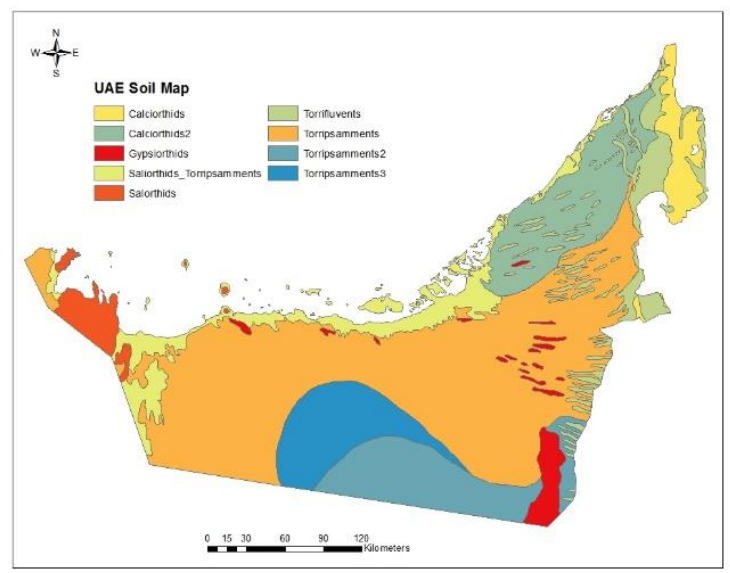

(c)

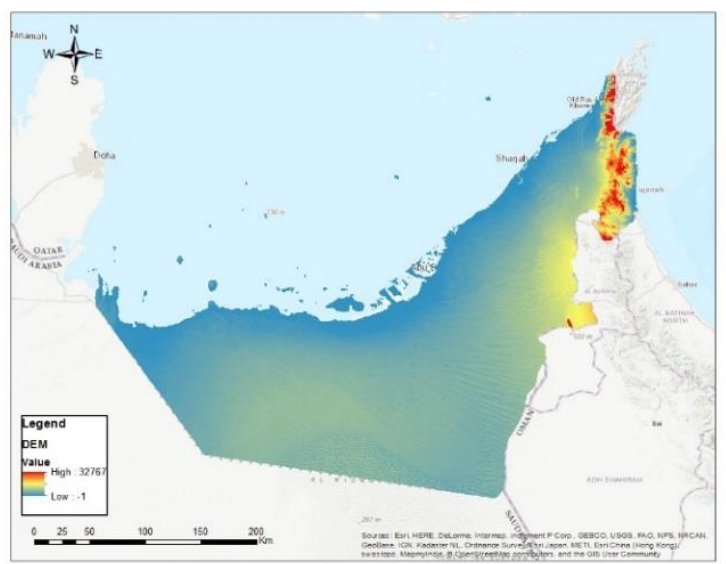

(b)

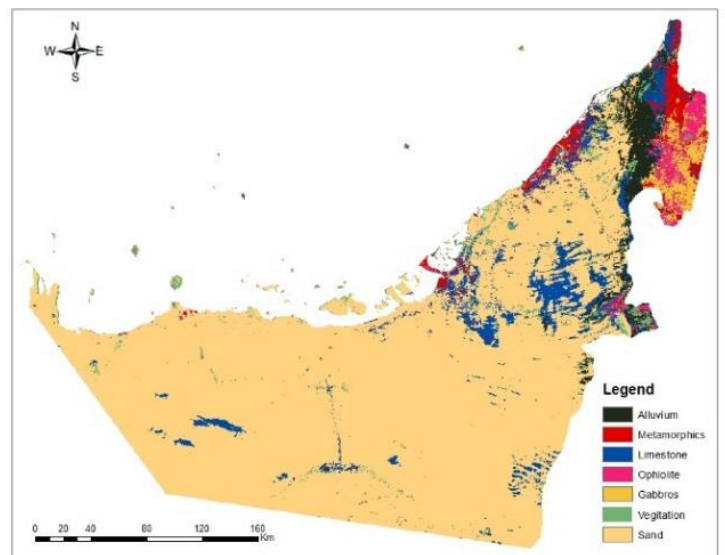

(d)

Figure 3. (a) Earthquake events- Zagros and the Makaran thrust; (b) ASTER 30m DEM; (c) Soil map; (d)Geology map

\subsection{Spatial Statistical Analysis}

When studying the distribution of earthquake events (point pattern analysis) first, a test for complete spatial randomness must be applied to reject the null hypothesis that proposes the pattern is random. This test allows distinguishing between random patterns which are of no interest and pattern that inhabits spatial relationships. Spatial statistical analysis procedures can be classified into global and local. Where local statistics investigate and recognize the spatial relationships, variations between variables, more specifically the presence of clusters or hot spots, for testing for heterogeneity and for determining the distance beyond which spatial effects between variables cease (Anselin 1995; Getis and Ord 1995). In this study local statistics: (1) Anselin local Moran's I, (2) Getis-Ord Gi*, (3) kernel density estimator $(\mathrm{KDE})$ will be applied to investigate the presence of clusters or hot spots using (1900-2015) earthquake events. Followed by, the directional distribution analysis to examine and locate the geographic distribution of earthquakes.

3.1.1 Kernel Density Estimator: is a nonparametric spatial interpolation technique for investigating the firstorder properties of a point event or line distribution to compute the event density (Silverman 1986; Xie and Yan, 2008). The function of KDE in a two-dimensional space is calculated as follows:

$$
f_{n}(x)=\frac{1}{n h} \sum_{i=1}^{n} k\left(\frac{d_{i}}{h}\right)
$$

Where $f_{n}(x)=$ density estimate at spatial unit $x$

$h$ = predefined bandwidth

$n=$ number of features near location $x$ within a radius of $h$,

$k$ = predefined kernel density function

The resulted surface from KDE shows a peak at the location of the event and decreases with the increasing of the distance from the event until reaching zero at the search radius distance from the event. In this study, KDE was applied to create a continuous surface map of earthquake density based on earthquakes magnitudes to show the location of the most powerful earthquakes. From these surfaces, it is possible to see how earthquakes densities vary across the Arabian plate.

3.1.2 Anselin local Moran's I: Anselin (1995) proposed a local Moran's I index of spatial association to recognize local clusters and the spatial outliers; it calculated as follows:

$$
I=\frac{\sum_{i} \sum_{k} w_{i j}\left(x_{i}-\bar{x}\right)\left(x_{j}-\bar{x}\right)}{s^{2} \sum_{i} \sum_{j} w_{i j}}
$$

Where $\quad \mathrm{x}_{\mathrm{i}}=$ attribute for feature $\mathrm{i}$

$\mathrm{X}=$ mean of the corresponding attribute,

$\omega i, j=$ spatial weight between feature $\mathrm{i}$ and $\mathrm{j}$.

Positive values for the Anselin local Moran's I index show that an event has neighboring events with the same high or low 
attribute values; and is part of a spatial cluster. On the other hand, negative values showed different values of neighboring events and considered to be an outlier. Moreover, the p-value must be less than $0.05(\mathrm{p}<0.05)$ to considered statistically significant.

3.1.3 Getis-Ord Gi*: The Getis-Ord Gi* statistic (Ord and Getis 1995; Mitchell 2005) detects statistically significant hot spots and cold spots within the events and can be calculated as:

$$
G i^{*}(d)=\frac{\sum_{j} w_{i j}(d) x_{j}-\bar{X} \sum_{j} w_{i j}(d)}{s \sqrt{\frac{n \sum_{j} w_{i j}{ }^{2}-\left(\sum_{j} w_{i j}(d)\right)^{2}}{n-1}}}
$$

Where $\quad x_{i}=$ attribute value for feature, $j$,

$$
\omega i, j=\text { spatial weight between feature } i \text { and } j
$$

$\mathrm{Gi}^{*}$ navigates locality based on nearby events or a set distance and gets a $\mathrm{Z}$ score. Statistically significant positive $\mathrm{Z}$ scores mean hotspot area, the higher the $\mathrm{Z}$ score is, the more intense the clustering of hotspots. Statistically significant negative $\mathrm{Z}$ score means cold spot area, the lesser the $\mathrm{Z}$ score, the more intense the clustering cold spots. When $\mathrm{Gi}^{*}$ value close to zero means the absence of clustering of; a hot or cold spot near the investigated event. That means the nearby events are near the mean value, or the investigated event is enclosed by a combination of high and low events.

3.1.4 The directional distribution: Directional distribution (standard deviational ellipse) will be used to measure the geographic distribution of earthquakes that will create standard deviational ellipses show the spatial characteristics of earthquake events such as directional trends, central tendency, and dispersion.

\subsection{Peak Ground Acceleration}

Earthquake hazard zonation depends on the seismological characterization of the site such as PGA. PGA is equal to the maximum ground acceleration that occurred during earthquake shaking at a specific location ("Peak ground acceleration," 2017). The attenuation relationship or Ground Motion Prediction Equations (GMPEs) describes the decrease in PGA (for an earthquake of (M) magnitude) with the distance from the earthquake epicenter (R). Since there were no seismograph networks in UAE until 2010, Ground Motion Prediction Equations (GMPEs), precise to UAE, are not available. All seismic hazard analysis performed for UAE used GMPEs developed for other geographical areas (Khan et al., 2013). In this study, PGA map has been developed using the attenuation relation addressed by IIEES (Zare, 2002). The general form of the attenuation equation motivated by that of Joyner and Boore (Joyner, 1981), is in the following form:

$\log A=C_{1} M_{w}+C_{2} R-C_{3} \log R+C_{i} S_{i}+(\sigma) P, i=1,2,3$

Where $\mathrm{A}=\mathrm{PGA} \mathrm{cm} / \mathrm{sec} 2$

$\mathrm{M}=$ earthquake magnitude (moment).

$\mathrm{R}=$ hotspot - distance $(\mathrm{km})$,

CI, C2 and C3: constants.

$\mathrm{Si}$ : site condition,

ci: site class (c1 for rock, $\mathrm{c} 2$ hard alluvium,etc

$\sigma=$ standard deviation

$\mathrm{P}=$ constant, $\mathrm{P}=0,1$

The following values have been calculated for Zagros horizontal component will be used in this study, $\mathrm{Cl}=0.399, \mathrm{C} 2=-0.0019$, $\mathrm{C} 3=1.0$ (for homogeneous space), $\mathrm{ci}=-1.047$ (site class for bedrock), $M=8.1$ (equals to the highest earthquake magnitude within the earthquake catalogue described earlier), $\mathrm{R}=$ distance raster form the hotspots earthquake points (Abdalla and AlHomoud, 2004)

\subsection{Weighted Overlay Analysis}

During the last decades, multi-criteria and analytic hierarchy process have been used in different areas such as industrial, educational, planning research areas, and in the emergency management process. These processes can effectively reduce the time needed to produce hazard maps. Spatial multi-criteria decision (MCD) typically involves a set of geographicallydefined alternatives (events) from which a choice of one or more alternatives is made concerning a given set of evaluation criteria (Jankowski, 1995; Malczewski, 1999). While AHP is one of the most usually used multi-criteria decision making (MCDM) tools. AHP is a method that allows the consideration of both objective and subjective factors in ranking alternatives. AHP assists the decision-making process by allowing decision-makers to organize the alternative solutions to a specific problem in a hierarchical decision model (Erden and Karaman, 2012). The first step is developing a comparison matrix at each level of the hierarchy, starting from the second level to the last level. The second step consists of computing the relative weights for each element of the hierarchy, and the third step originates by estimating the consistency ratio to check the consistency of the judgments (Saaty, 1980), it can be computed based on following equations (5-7):

$$
\begin{aligned}
& \mathrm{CI}=\frac{\lambda_{\max }-\mathrm{n}}{\mathrm{n}-1} \\
& \mathrm{RI}=\frac{1.98(\mathrm{n}-1)}{\mathrm{n}} \\
& \mathrm{CR}=\frac{\mathrm{CI}}{\mathrm{RI}}
\end{aligned}
$$

Where $\quad \mathrm{CI}=$ consistency index

$\mathrm{RI}=$ randomized index

$\mathrm{CR}=$ consistency ratio

$\mathrm{n}=$ order of the compression matrix

For the process of identifying hazard zones, five factors were used and utilized for pair-wise comparison (Peak Ground Acceleration (PGA), distance from major faults, slope, soil and geology maps. As shown in Table 2. For consistency measurements, the required consistency was satisfied $(\mathrm{CR}<0.1)$ with a $\mathrm{CR}$ value equal to 0.038 . The highest weights were associated with PGA and distance from the major faults,

\begin{tabular}{|l|l|l|l|l|l|}
\hline Criterion & PGA & Fault & Slope & Soil & Geology \\
\hline PGA & 1.000 & 1.000 & 6.000 & 2.000 & 1.500 \\
Fault & 1.000 & 1.000 & 6.000 & 2.000 & 1.500 \\
Slope & 0.167 & 0.167 & 1.000 & 0.333 & 0.250 \\
Soil & 0.500 & 0.500 & 3.000 & 1.000 & 0.750 \\
Geology & 0.667 & 0.667 & 1.333 & 1.333 & 1.000 \\
\hline
\end{tabular}

Table 2. AHP pair wise comparison matrix

An explanation of each of the factors considered in this study is provided below.

3.3.1 Distance from the faults: Earthquake affects decreases as the distance from the earthquake epicenter increases. In this study the distance from the two faults, Zagros Fold and Thrust Belt and Makran Subduction Zone, which considered as the only two fault systems that have a direct effect on the seismicity of UAE as stated by (Abdalla and Al-Homoud, 2004). The Euclidian distance tool has been used to determinate the distance, the reverse effect of the distance from fault lines to sites had been modeled by reclassifying the distance raster into five classes, Table 3. 
3.3.2 Soil classification map: Soil map is an efficiency factor that contributes in investigating the seismicity of an area. In this study atlas soil map for the study area (acquired from University of Sharjah) has been scanned, georeferenced and digitized, Figure 3-c. The description of soil units is based on soil association instead of on a single soil category. The soil classes were determined concerning (Yagoub, 2015) study which states that the Torripsamments, clay-rich soil type, is not vulnerable to seismic activity. While Torrifluvents considered being more vulnerable to any seismic activity. According to (Yagoub, 2015) the soil map has been classified into two soil classes and then ranked and weighted, Table 3.

3.3.3 Field topography: The influence of topography is an important factor in the mapping of the earthquake hazards. Even though there is no large variation in the slope along the study area but due to the population growth and expansion of urban areas near the mountains, slope effect had to be considered in this study. Increase factors of topography are derived from the study area DEM. The DEM data shown as slope angles, Figure 3-b, had been reclassified into four classes. Then the raster map had been ranked and weighted according to its influence on the earthquake effects, Table3.

3.3.4 Geology: Geology classification maps can be used as identifies elements for different emergency management procedures. In this study, Landsat 8 free of cloud cover for the year 2017 were downloaded from USGS web site then mosaicked. Band ratio combinations $(6,7,4)$ made the input for the supervised classification, where the ground truth samples were taken from Atlas UAE geology map, Table 3

\begin{tabular}{|c|c|c|c|}
\hline Themes & Class value & Rank & $\begin{array}{l}\text { Weightl } \\
\text { Priority }\end{array}$ \\
\hline \multirow[t]{5}{*}{ PGA } & Very high & 9 & \multirow[t]{5}{*}{$30 \%$} \\
\hline & High & 7 & \\
\hline & Moderate & 5 & \\
\hline & Low & 3 & \\
\hline & Very low & 1 & \\
\hline \multirow{5}{*}{$\begin{array}{l}\text { Distance } \\
\text { from the } \\
\text { faults }\end{array}$} & $118-200 \mathrm{Km}$ & 9 & \multirow[t]{5}{*}{$30 \%$} \\
\hline & $200-300 \mathrm{Km}$ & 7 & \\
\hline & $300-400 \mathrm{Km}$ & 5 & \\
\hline & $400-500 \mathrm{Km}$ & 3 & \\
\hline & $>500 \mathrm{Km}$ & 1 & \\
\hline \multirow[t]{4}{*}{ Slope } & $30<$ & 9 & \multirow[t]{4}{*}{$5 \%$} \\
\hline & $15-30$ & 7 & \\
\hline & $10-15$ & 5 & \\
\hline & $0-10$ & 3 & \\
\hline \multirow[t]{2}{*}{ Soil } & $\begin{array}{l}\text { Torripasmments2, } \\
\text { and 3, Saliorthids_ } \\
\text { Torripasmments } \\
\text { and Calciorthids }\end{array}$ & 9 & \multirow[t]{2}{*}{$15 \%$} \\
\hline & $\begin{array}{l}\text { Torrifluvents, } \\
\text { Gypsiorthids, } \\
\text { Salorthids, and } \\
\text { Torriorthents }\end{array}$ & 4 & \\
\hline \multirow[t]{5}{*}{ Geology } & Sand & 9 & \multirow[t]{5}{*}{$20 \%$} \\
\hline & Alluvial & 7 & \\
\hline & Limestone & 5 & \\
\hline & Metamorphic & 3 & \\
\hline & $\begin{array}{l}\text { Gabbro and } \\
\text { Ophiolite }\end{array}$ & 1 & \\
\hline
\end{tabular}

Table 3. Weighting and ranking of considered factors

\section{RESULTS AND CONCLUSIONS}

\subsection{Spatial Statistics}

Earthquake catalog includes 13,156 events from 1900 to 2015 with $8.1 \mathrm{Mw}$ as the maximum earthquake magnitude had been statistically investigated using Local statistics: KDE, Anselin local Moran's I, and Getis-Ord Gi* to identify the occurrence and location of clusters or hot spots across the Arabian plate. Figure 4-a shows the hot spot patterns of earthquake occurrence using KDE where the density at each location based on earthquakes magnitudes has been identified. After examining Figure 4-a, large cluster in the southern part of Iran, south western part of Yemen and south of Jordan can be observed.

Figure 4-b shows the locations of earthquakes after applying Anselin local Moran's I statistics. Anselin local Moran's I statistics uses a degree of spatial autocorrelation of earthquake occurrence weighted by earthquakes magnitude to recognize significant clusters and spatial outliers in the sample. Spatial clusters are indicated by blue and red dots. The red dots show earthquakes with high magnitudes that are surrounded by high magnitudes earthquakes. In contrast, the blue dots indicate low magnitude earthquakes surrounded by other earthquakes of low magnitudes. The light green and light orange dots indicate the presence of spatial outliers, which could be low magnitude events surrounded by high events and vice versa. Spatial clusters of earthquakes recognized in specific locations that surround the Arabian plate. The high-high clusters appear in the northeastern part of the Arabian plate, while the low-low clusters appear at the south western part of the Arabian plate.

Figure 4-c shows the location of earthquakes around the Arabian plate with significant Getis-Ord Gi* statistics. The Getis-Ord Gi* identifies hot spots of earthquake occurrence. Hot spots mean high magnitude events are surrounded by other high magnitude earthquakes; while cold spots mean low magnitude surrounded by low magnitude events. The red and blue dots in Figure 4-c indicate significant hot and cold spots, respectively. The GetisOrd Gi* analysis shows statistically significant hot spots at the northern part of the Arabian plate specifically north Iraq and east of Turkey at the fold and thrust belt of Bitlis- Zagros and the East Anatolian fault. Moreover, significant hot spots can be observed at the eastern part of the Arabian plate, with big concertation in the western part of Pakistan this could be due to the tectonic contact between the three main tectonic plates Eurasian, Indian and Arabian plates. However, the significant cold spots can be observed in the south western part of the Arabian plate, the western part of Jordan along the red sea, and south part of Yemen. Another cold spots concentration can be found in the south western part of Iran, north of UAE.

Based on the outcomes of applying the Anselin local Moran's I and the Getis-Ord $\mathrm{Gi}^{*}$ statistics, earthquakes with high magnitudes are focused in south western part of Pakistan, and the northern part of Iraq. These areas can be considered as seismically active. Getis-Ord Gi* statistics provides more local details about the clusters than Anselin local Moran's I statistics. For example, the Anselin local Moran's I indicated that the northeastern part of the Arabian could be recognized as an area of high magnitude clusters, while the Getis-Ord $\mathrm{Gi}^{*}$ analysis provides more spatial concertation of hot spots location that can be labeled as most risky or dangerous areas.

Figure 4-d shows the results of investigating directional distribution across hot spots to know whether or not the seismic activity at the Arabian plate reveals a directional trend. The results indicate that hot spots are located in the northern, eastern part while the cold spots ellipse is located in the central part of the Arabian plate. 


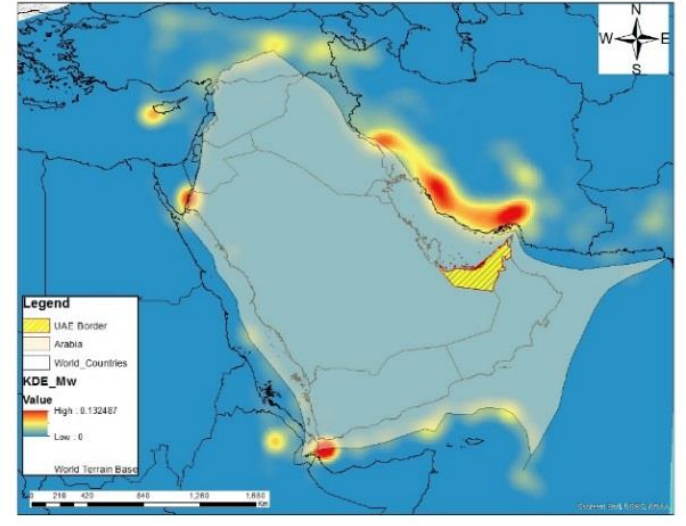

(a)

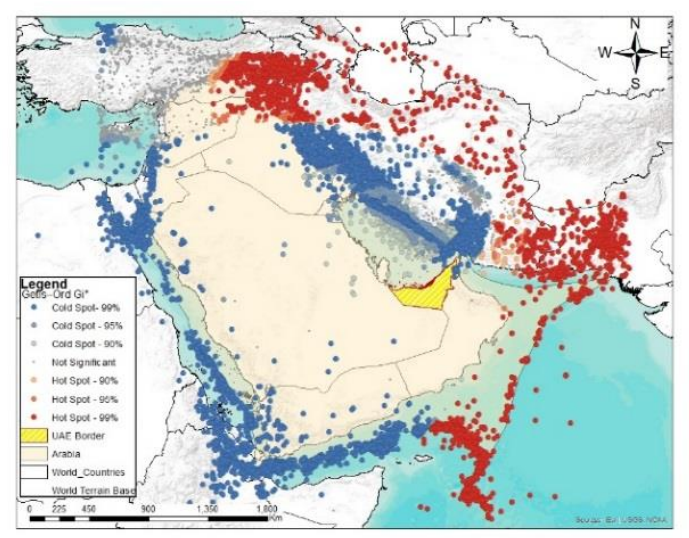

(c)

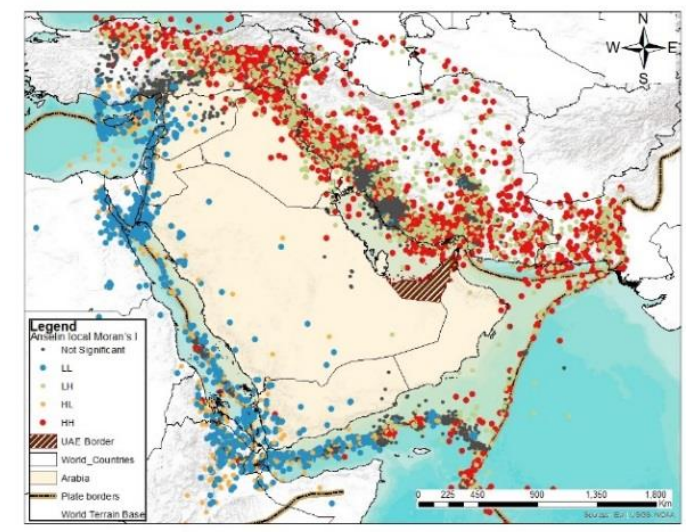

(b)

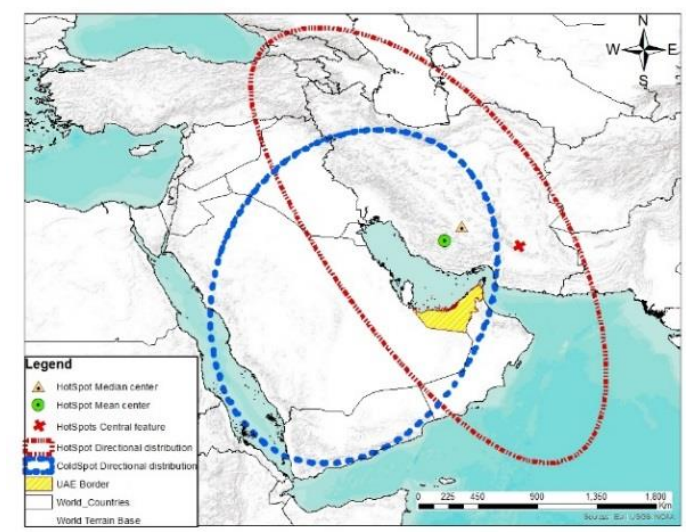

(d)

Figure 4. Spatial statistics for earthquake events(a) KDE; (b) Anselin local Moran's I (c) Getis-Ord Gi*; (d) Directional distribution

\subsection{Weighted Overlay and AHP}

According to expert's opinion, literature review, and after generating the pairwise comparison matrix each of the considered factors (that includes PGA, and distance from main faults, slope, soil, geology maps) had been ranked and weighted, Table 3. It is obvious that the source to site distance parameter given the highest weight for every disciplines evaluation, while the slope parameter is given the lowest weight in the evaluation of all disciplines, however, geologists select the soil classification map as the most important parameter for the earthquake hazard map creation (Erden and Karaman, 2012). The generated maps from the ranking criteria for each parameter visualize and describe the effect of these parameters at every location within the study area. It can be observed that the amplification effect of the PGA, slope, and source to site distance parameters reach its highest at the Fujairah and Old Ras al-Khaimah emirates, while the amplification effect of the geology and soil parameters reach its highest at the middle and southern parts of the study area. Based on the assigned weights of the factors the potential seismic hazard zones of earthquake-prone areas were calculated. Five hazard zones had been developed according to the region earthquake hazard: very high, high, moderate, low and very low. It is obvious from Figure 5 that the "very high" hazard zone is located in Fujairah city covering $202 \mathrm{~km}^{2}$ highly populated spot. On the other hand, $7436 \mathrm{~km} 2$ (11\% of UAE area) fallen within high hazard zone that covers some areas within Fujairah, Ras AlKhaimah, and Sharjah city. It has been found that Sharjah and Dubai cities located from "High" to moderate zones while Abu Dhabi city stands relatively far from seismic hot spots and major faults and placed in the low seismic hazard zone. Therefore, vulnerability analysis, long-term land-use planning, emergency preparedness planning, and mitigation procedures should be considered and conducted in these areas.

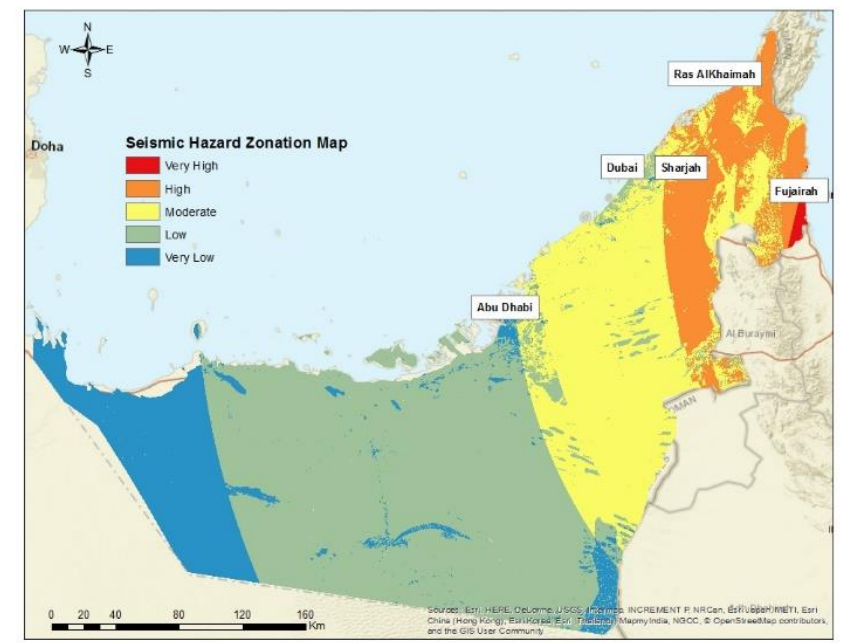

Figure 5. UAE Seismic Hazard Zonation Map 


\section{CONCLUSION AND FUTURE WORK}

This study represents an effort to investigate the temporal and spatial distribution of earthquakes at the Arabian plate between the years 1900 and 2015 and its correlation with UAE location. Earthquake events were found to occur in cluster basically in the northern and southeastern parts of the Arabian plate. Distances from Arabian plate earthquakes hotspots location had been used to generate PGA maps for the UAE. In this study, various geospatial factors had been considered to locate the hazardous zones and develop UAE SHZM. These factors include distance map from two major faults, Zagros Fold and Thrust Belt and Makran, PGA, geology, soil, and slope, maps. The created SHZM shows that areas within downtown and coastal areas at Fujairah emirates are more vulnerable and its population is on a very high-risk zone, $10.78 \%$ of total study area falls under the high-risk zone, $25.91 \%$ under moderate risk, and $48.95 \%$ under low-risk zone. The SHZM map is expected to increase the awareness for earthquake hazards avoidance at the time of need, where different emergency management procedures should be considered. However, the accuracy of this study results depends on the used data, the attenuation equation, and percent influence weight determination. Evaluation of local site characteristics such as topographic effects, geotechnical characteristics of sediments, liquefaction potential, fault/focal mechanism, etc. should be considered. Moreover, examination needs to be studied and adjusted when effective earthquake data become available and a dependable attenuation relation is developed since the attenuation relation used in this study is for Zagros fold zone. The workflow used in this study could be used for vulnerability analysis.

\section{REFERENCES}

Abdalla, J, Al-homoud, A. , 2004. Seismic hazard assessment of the United Arab Emirates and its surroundings. Journal of Earthquake Engineering, 8(6), 817-837.

Al-Ahmadi, K., Al-Amri, A., See, L., 2013. A spatial statistical analysis of the occurrence of earthquakes along the Red Sea floor spreading: clusters of seismicity. https://doi.org/10.1007/s12517-013-0974-6.

Al-Amri, A., Punsalan, B., \& Uy, E. 1998. Spatial distribution of the seismicity parameters in the Red Sea regions. Journal Of Asian Earth Sciences, 16(5-6), 557-563.

Aldama-Bustos, G., Bommer, J., Fenton, C., \& Stafford, P. (2009) Probabilistic seismic hazard analysis for rock sites in the cities of Abu Dhabi, Dubai and Ra's Al Khaymah, United Arab Emirates. Georisk: Assessment And Management Of Risk For Engineered Systems and Geohazards, 3(1), 1-29.

AL-Ruzouq, R., Hamad, K., Shanableh, A., Khalil, M., 2017. Infrastructure growth assessment of urban areas based on multi-temporal satellite images and linear features. Ann. GIS 1-19.

Ambraseys, N., Srbulov, M. 1994. Attenuation of earthquake-induced ground displacements. Earthquake Engineering \& Structural Dynamics, 23(5), 467-487.

Ansal, A., Akinci, A., Cultrera, G., Erdik, M., Pessina, V., Tönük, G.,Ameri, G.2009. Loss estimation in Istanbul based on deterministic earthquake scenarios of the Marmara Sea region (Turkey). Soil Dynamics and Earthquake Engineering, 29(4), 699-709.

Anselin L (1995) Local indicators of spatial association-LISA. Geogr Anal 27:93-115.

Barakat, S., Shanableh, A., and Malkawi, A., 2008. A Comparative Earthquakes Risk Assessment Approach Applied to the United Arab Emirates, Jordan Journal of Civil Engineering, Volume 2, No. 2.

Chang, N., Parvathinathan, G., Breeden, J.B., 2008. Combining GIS with fuzzy multicriteria decision-making for landfill siting in a fast-growing urban region $87,139-153$.

Cinicioglu, S.F., Bozbey, I., Oztoprak, S., Kelesoglu, M.K., 2007. An integrated earthquake damage assessment methodology and its application for two districts in Istanbul, Turkey 94, 145-165.

Danese M., Lazzari M., Murgante B. (2008) Kernel Density Estimation
Methods for a Geostatistical Approach in Seismic Risk Analysis: The Case Study of Potenza Hilltop Town (Southern Italy).

Deif, A., Al-shijbi, Y., El-hussain, I., Ezzelarab, M., Mohamed, A.M.E., (2017). Journal of Asian Earth Sciences Compiling an earthquake catalog for the Arabian Plate, Western Asia. J. Asian Earth Sci. 147, 345-357.

Erden, T., Karaman, H., 2012. Analysis of earthquake parameters to generate hazard maps by ${ }^{*}$, ekmece region integrating AHP and GIS for K UC 475-483.

Harnan, E. 2013. New earthquake code for Dubai's tall buildings. The National. Retrieved 2 December 2017, from https://www.thenational.ae/uae/new-earthquake-code-for-dubai-s-tallbuildings-1.260158.

Jankowski, P. (1995). Integrating geographical information-systems and multiple criteria decision-making methods, Int. J. Geogr. Inf.Syst., 9, 251-273.

Joyner, W. B., and Boore, D. M. 1981.Peak horizontal acceleration and velocity from strong-motion records from the 1979 Imperial Valley, California, Earthquake,Bulletin of the Seismological Society of America 71 (6), 201 1-2038

Khan, Z., El-Emam, M., Irfan, M., \& Abdalla, J. 2013. Probabilistic seismic hazard analysis and spectral accelerations for the United Arab Emirates. Natural Hazards, 67(2), 569-589

Korrat, I., Hussein, H., Marzouk, I., Ibrahim, E., Abdel-Fattah, R., \& Hurukawa, N. (2006). Seismicity of the northernmost part of the Red Sea (1995-1999). Acta Geophysica, 54(1).

Liu, J., Mason, P., Yu, E., Wu, M., Tang, C., Huang, R., \& Liu, H. (2012). GIS modeling of earthquake damage zones using satellite remote sensing and DEM data. Geomorphology, 139-140, 518-535.

Malczewski, J. 1999.: Gis and multicriteria decision analysis, J. Wiley \& Sons, New York, xv, 392 pp.

Malkawi A., Barakat S., Bdour W. A., Omar M., Altoubat S. and Shanableh A., 2007. Seismic hazard assessment and earthquake risk in the United Arab Emirates, Sharjah, UAE.

Mitchell A 2005 .The ESRI guide to GIS analysis, spatial measurements, and statistics. ESRI, Redlands, CA.

Mohanty, W., Walling, M., Nath, S., \& Pal, I. (2006). First Order Seismic Microzonation of Delhi, India Using Geographic Information System (GIS). Natural Hazards, 40(2), 245-260.

Ncema.gov.ae. 2018. The Supreme Council for National Security National Emergency Crisis and Disaster Management Authority. Available at: https://www.ncema.gov.ae Accessed 14 Jan. 2018.

Ord JK, Getis A 1995. Local spatial autocorrelation statistics: distributional issues and an application. Geogr Anal 27(4):286-306.

Pal, I., Nath, S., Shukla, K., Pal, D., Raj, A., Thingbaijam, K., \& Bansal, B. (2007). Earthquake hazard zonation of Sikkim Himalaya using a GIS platform. Natural Hazards, 45(3), 333-377.

Pascucci, V., Free, M.W., Lubkowski, Z.A., 2008. Seismic hazard and seismic design requirements for the Arabian Peninsula region. Peak ground acceleration. (2017). En.wikipedia.org.

Saaty, T. L. 1980.: The analytic hierarchy process: Planning, setting priorities, resource allocation, McGraw-Hill International Book Co., New York, London, xiii, 287 pp.

Sigbjornsson, R., elnashai, A. (2006). Hazard assessment of Dubai, United Arab Emirates, for close and distant earthquakes. Journal of Earthquake Engineering, 10(5), 749-773.

Silverman BW 1986 Density estimation for statistics and data analysis.Chapman Hall, London, UK.

Simpson, A. 1996. Attenuation of Strong Ground-motion Incorporating Near-surface Foundation Conditions, Ph.D. dissertation, University of London, London, Retrieved on 24 October from http://ethos.bl.uk/OrderDetails.do?uin=uk.bl.ethos.243905

Xie, Z., Yan, J., 2008. Computers, Environment and Urban Systems Kernel Density Estimation of traffic accidents in a network space. Comput. Environ. Urban Syst. 32, 396-406.

Yagoub, M.M., 2015. Spatio-temporal and hazard mapping of Earthquake in UAE (1984 -2012): Remote sensing and GIS application. https://doi.org/10.1186/s40677-015-0020-y

Zare, M. 2002.Attenuation relation and coefficients of movement in Iran, International Institute of Earthquake Engineering and Seismology. 